\title{
THE RELATIONSHIP OF JOB SATISFACTION AND INTERNAL LOCUS OF CONTROL WITH TURNOVER INTENTION ON NURSES AT CHARLIE HOSPITAL, KENDAL
}

\author{
Gufa Bagus Pamungkas \\ Faculty of Economics, \\ Sultan Agung Islamic University, Jalan Raya Kaligawe, KM 4. Semarang, 50112, Indonesia \\ Email: bagusgufa@gmail.com \\ Heru Sulistyo \\ Faculty of Economics, \\ Sultan Agung Islamic University, Jalan Raya Kaligawe, KM 4. Semarang, 50112, Indonesia \\ Email: heru@unissula.ac.id
}

\begin{abstract}
Abstrak: Tingkat turnover perawat di rumah sakit selalu menduduki peringkat pertama dalam beberapa dekade terakhir, studi terdahulu menganggap kepuasan kerja dan locus of control internal dapat menurunkan angka turnover intention. Kepuasan kerja merupakan kondisi psikologis pekerja terhadap suatu pekerjaan baik berupa perasaan senang maupun tidak senang, sedangkan locus of control internal yaitu kepercayaan seseorang kepada dirinya sendiri sebagai pengendali nasibnya, Penelitian ini bertujuan untuk mendeskripsikan dan menguji hubungan kepuasan kerja dan locus of control internal terhadap turnover intention pada perawat di Rumah Sakit Charlie Hospital, Kendal. Penelitian ini adalah penelitian deskriptif kuantiatif, serta pengambilan data dilakukan dengan menggunakan kuisioner dengan teknik purposive sampling. Subjek pada penelitian merupakan perawat Rumah Sakit Charlie Hospital yang berjumlah 35 perawat. Analisis data yang digunakan pada penelitian ini yaitu menggunakan analisis regresi. Hasil dari analisis deskriptif diperoleh data bahwa tingkat kepuasan kerja perawat tergolong puas, dan cenderung memiliki locus of control internal serta tingkat turnover intention perawat tergolong tinggi dan dari hasil analisis regresi didapatkan bahwa nilai signifikansi sebesar 0.822 untuk kepuasan kerja, serta 0.765 untuk locus of control internal yang berarti bahwa tidak terdapat hubungan antara kepuasan kerja dan locus of control internal terhadap turnover intention pada perawat di Rumah Sakit Charlie Hospital.
\end{abstract}

Kata kunci: Stres; Tenaga Kesehatan; Dokter Gigi.

Absract: Nurse turnover rates in hospitals have always been ranked first in the last few decades, previous studies have considered job satisfaction and internal locus of control can reduce turnover intention. Job satisfaction is a psychological condition of workers towards a job in the form of both happy and unhappy feelings, while the internal locus of control is one's trust in himself as the controller of his destiny. This study aims to describe and test the relationship between job satisfaction and internal locus of control for turnover intention to nurses at Charlie Hospital, Kendal. This research is a descriptive quantitative study, and data collection is done by using a questionnaire with purposive sampling technique. Subjects in this study were nurses at Charlie Hospital, amounting to 35 nurses. Analysis of the data used in this study is to use regression analysis. The results of the descriptive analysis obtained data that the level of nurse job satisfaction is classified as satisfied, tends to have an internal locus of control and the level of nurse turnover intention is high and from the results of the regression analysis found that a significance value of 0.822 for job satisfaction, and 0.765 for internal locus of control which means that there is no relationship between job satisfaction and internal locus of control on turnover intention in nurses at charlie hospital.

Keywords: Stress; Health Workers; Dentists.

Article History: Received 2020-03-07; Revised 2020-04-08; Accepted 2020-04-13

Gufa Bagus Pamungkas ${ }^{2}$, Heru Sulistyo ${ }^{2}$ - The Relationship Of Job Satisfaction And Internal Locus Of Control With Turnover...

[Vol 11, No 1 (2020): April 2020] JBTI 


\section{PENDAHULUAN}

Rumah sakit merupakan organisasi yang unik, karena beberapa aspek melebur jadi satu antara padat teknologi, padat karya dan padat modal, sehingga pengelolaan rumah sakit menjadi disiplin ilmu tersendiri yang menghasilkan dua hal sekaligus, yaitu keilmuan bidang teknologi dan perilaku manusia di dalam organisasi (Purnamasari dan Kapalawi, 2013). Salah satu sumber daya manusia yang sangat substansial di rumah sakit yaitu tenaga keperawatan karena perawat merupakan tulang belakang dari sebuah pelayanan kesehatan. Agar dapat mewujudkan tercapainya pelayanan kesehatan yang berkualitas dan berkinerja tinggi diperlukan tenaga keperawatan yang profesional, memiliki kemampuan intelektual, teknikal dan interpersonal, bekerja berdasarkan standar praktik, memperhatikan kaidah etik dan moral (Sarah dkk, 2015). Namun penelitian sebelumnya menerangkan bahwa perawat merupakan tenaga kesehatan yang memiliki tingkat turnover yang cukup tinggi di rumah sakit yaitu dengan prosentase sebesar 16,5\% dan diproyeksikan akan selau meningkat dalam dekade berikutnya (Mazurenko dkk, 2015).

Profesional sumber daya manusia di rumah sakit telah memahami bahwa tenaga kesehatan di rumah sakit merupakan aset utama, sehingga apa yang menyebabkan tenaga keperawatan berhenti dari pekerjaan mereka akan terus dicari (Soeroso, 2003), Aktivitas turnover karyawan akan mempengaruhi berbagai aktivitas pekerjaan yang terdapat pada sebuah perusahaan dan dapat juga mempengaruhi prestasi kerja karyawan secara komprehensif (Pawesti dan Wikansari, 2016) dan jika masalah turnover ini terjadi di rumah sakit maka dapat mengganggu jalannya pelayanan kesehatan di rumah sakit, dimana pelayanan kesehatan di rumah sakit seharusnya berjalan secara kontinuitas dan tanpa henti (Allen dkk, 2010). selain itu, dari sisi manajemen proses turnover karyawan bisa menghabiskan biaya yang mahal, dan seringkali tenaga kesehatan pengganti memiliki kemampuan yang tidak dimiliki tenaga kesehatan sebelumnya, serta setelah keluarnya tenaga kesehatan di rumah sakit juga mempengaruhi semangat kerja tenaga kesehatan lain, memacu desas-desus, dan seringkali membuka pintu bagi tenaga kesehatan lain untuk juga meninggalkan rumah sakit (Mattox dan Darryl L., 2005).

Turnover merupakan suatu hal yang tidak inginkan oleh sebuah perusahaan. Turnover merupakan masalah lazim pada pengelolaan sumber daya manusia yang akan selalu dihadapi sebuah perusahaan (Pawesti dan Wikansari, 2016). Pergantian karyawan selama tahun pertama pekerjaan bisa menjadi masalah yang besar. Oleh sebab itu, rumah sakit perlu menerapkan rencana strategis sebagai upaya peningkatan retensi karyawan, diharapkan upaya tersebut dapat membantu mengurangi pergantian karyawan atau turnover pada tahun pertama (Daniels, dkk. 2013) Penerapan strategi yang tepat dalam memprediksi,menganalisa, dan mengendalikan turnover karyawan di rumah sakit dapat mengurangi biaya pergantian karyawan dan membantu rumah sakit agar tetap bertahan dan bahkan berkembang dalam perekonomian yang menantang (Jeon dan Yom 2014).

Menurut Firdaus (2017) penyebab terjadinya turnover pada karyawan yang paling dominan yaitu kepuasan kerja, Kepuasan kerja adalah keadaan emosional menyenangkan atau tidak menyenangkan yang dirasakan karyawan dalam menanggapi pekerjaan mereka. Aspek kognitif pada kepuasan kerja yaitu kepercayaan karyawan tentang pekerjaan dan situasi pekerjaan: Bahwa karyawan yakin bahwa pekerjaannya menarik, merangsang, membosankan atau menuntut. Aspek perilaku pekerjaan adalah kecenderungan perilaku karyawan atas pekerjaannya yang ditperlihatkan lewat pekerjaan yang dilakukan, terus bertahan di posisinya, atau bekerja secara teratur dan disiplin (Firdaus, 2017). Penelitian lain juga mengatakan hal yang sama yaitu terjadi pengaruh yang signifikan secara simultan dari kepuasan kerja dengan turnover intention. Variabel-variabel yang diteliti dari kepuasan kerja yaitu variabel Kepuasan pada Pembayaran, Kepuasan pada Pekerjaan, Kepuasan pada Rekan Kerja, Kepuasan pada Promosi dan Kepuasan pada supervisor (Sari dkk, 2015). Pendapat lain juga menerangkan hal yang relevan yaitu bahwa semakin tinggi kepuasan yang diperoleh seorang karyawan maka semakin rendah angka turnover intention (Ikhwanto, 2015).

Gufa Bagus Pamungkas ${ }^{2}$, Heru Sulistyo ${ }^{2}$ - The Relationship Of Job Satisfaction And Internal Locus Of Control With Turnover... [Vol 11, No 1 (2020): April 2020] JBTI 
Karyawan pada umumnya akan memberikan komitmennya secara penuh untuk tetap loyal pada sebuah perusahaan jika kepuasan kerja didapatkan oleh karyawan tersebut, sementara ketidakpuasan akan pekerjaan dapat berpengaruh pada keputusan untuk berhenti bekerja di sebuah perusahaan. Kepuasan kerja merupakan keadaan emosional yang menyenangkan atau emosi positif yang berasal dari penilaian pekerjaan atau pengalaman kerja seseorang selama bekerja di sebuah perusahaan. Ketidakpuasan akan pekerjaan sering diidentifikasikan sebagai salah satu alasan penyebab turnover intention. Turnover intention adalah keinginan seseorang untuk keluar atau berhenti dari perusahaan tempat dirinya bekerja, hal tersebut terjadi setelah individu yang bersangkutan melakukan evaluasi terhadap pekerjannya atau erat hubungannya dengan tempat dia bekerja sekarang (Sari dkk, 2015).

Penelitian yang dilakukan oleh lin dan ding pada tahun 2005, menganggap bahwa turnover dapat diturunkan melalui karyawan yang memiliki locus of control ke arah internal. Hal tersebut disebabkan tipe locus of control internal menimbulkan kepercayaan bahwa individu bertanggung jawab atas keberhasilan atau kegagalan mereka sendiri, sehingga membuat mereka akan bekerja dengan sungguh-sungguh agar mendapatkan kesuksesan di tempat kerja mereka (Lin dan Ding, 2005). Peneliti lain juga berpendapat sama yaitu Locus of control Internal menunjukkan hubungan positif yang lebih kuat daripada locus of control eksternal pada masalah turnover karyawan, atau bisa dikatakan karyawan yang memiliki locus of control internal memiliki kemungkinan yang kecil untuk berpindah dari pekerjaan atau berhenti dari pekerjaan (Blau, 1987). locus of control berperan penting karena dianggap terkait dengan persepsi dan kebutuhan pekerjaan dan sangat penting untuk pencapaian serta penting dalam organisasi yang terkait dengan pekerjaan (Ripiinen, 2010).

Turnover pada tenaga keperawatan juga pernah diteliti sebelumnya, alasan perawat berhenti dari pekerjaan mereka yaitu tingkat stres yang tinggi, tidak puas dengan kepemimpinan organisasi, tidak puas dengan jenjang karir yang ditawarkan, dan tidak diberikan kompensasi secara memadai, namun peneliti menyatakan penelitiannya mengalami keterbatasan karena mungkin masih ada variabel variabel lain yang perlu diteliti terkait turnover pada perawat (Mazurenko dkk, 2015).

Berdasarkan uraian diatas peneliti bermaksud meneliti hal-hal yang menjadi permasalahan diatas yaitu terkait tingginya angka turnover tenaga keperawatan di rumah sakit terutama yang menjadi fokus adalah perawat yang bekerja pada tahun pertama pekerjaan. Hal tersebut dikaitkan dengan dugaan bahwa kepuasan kerja dan locus of control internal dapat menurunkan angka turnover intention. Sehingga peneliti bermaksud mendeskripsikan dan menguji hubungan kepuasan kerja, locus of control internal dengan turnover intention pada perawat.

Peneliti telah menemukan rumah sakit yang cocok menjadi tempat akan dilakukannya penelitian yaitu di Rumah Sakit Charlie Hospital, Kendal. Rumah Sakit Charlie Hospital merupakan rumah sakit tipe D yang teletak di Jalan Raya Ngabean, Boja, Kendal. Rumah Sakit ini mulai beroperasi semenjak September 2019, sehingga dalam kata lain semua perawat yang bekerja di Rumah Sakit Charlie Hospital, Kendal masih kurang dari satu tahun bekerja disana. Selain itu, berdasarkan wawancara dengan bagian sumber daya manusia Rumah Sakit Charlie Hospital menghasilkan data bahwa turnover rate perawat sudah mencapai $6,67 \%$ pada 5 bulan pertama beroperasional, dengan adanya penelitian ini diharapkan dapat menurunkan turnover intention pada tenaga keperawatan agar rumah sakit dapat terus berkembang.

\section{METODE PENELITIAN}

Desain penelitian yang digunakan dalam penelitian ini yaitu penelitian deskriptif kuantitatif. Penelitian deskriptif yaitu mengumpulkan data berdasarkan faktor- faktor yang menjadi pendukung terhadap objek penelitian, kemudian menganalisa faktor- faktor tersebut untuk dicari peranannya (Prabowo dan Heriyanto, 2013), sedangkan penelitian kuantitatif merupakan pendekatan untuk menguji teori objektif dengan menguji hubungan antar variabel (Wahidmurni, 2017). Variabel

Gufa Bagus Pamungkas ${ }^{2}$, Heru Sulistyo ${ }^{2}-$ The Relationship Of Job Satisfaction And Internal Locus Of Control With Turnover...

[Vol 11, No 1 (2020): April 2020] JBTI 
bebas dalam penelitian ini adalah turnover intention. Variabel terikatnya adalah kepuasan kerja dan Locus of control internal.

Alat pengumpulan data menggunakan kuisioner turnover intention dan kuisioner kepuasan kerja dimana kuisioner turnover intention terdiri dari tiga aspek yakni aspek personal, organisasi dan karakteristik pekerjaan, dengan 9 item favorable dan 5 item unfavourable, sedangkan pada kuisioner kepuasan kerja berdasarkan aspek-aspek yang dapat mempengaruhi kepuasan kerja. Terdapat sembilan aspek dalam kepuasan kerja, yaitu kepuasan terhadap gaji, kesempatan promosi, supervise atau atasan, tunjangan, penghargaan terhadap hasil kerja, prosedur kerja, rekan kerja, karakteristik pekerjaan dan komunikasi. Terdapat empat pilihan jawaban, 1 (Sangat Tidak Sesuai/STS), 2 (Tidak Sesuai/ TS), 3 (Susuai/ S), 4 (Sangat Sesuai/ SS) untuk kuisioner kepuasan kerja sedangkan untuk kuisioner turnover intention memilik angka kebalikanya yaitu, 1 (Sangat Sesuai/ SS), 2 (Susuai/ S), 3 (Tidak Sesuai/ TS), 4 (Sangat Tidak Sesuai/STS), sedangkan pada kuisioner terkait locus of control internal hanya menggunakan dua pilihan yaitu 1 (Benar), 0 (Salah) agar dapat mengetahui kearah mana locus of internal dari subjek (Ramadhani, 2019). Kuisioner disebarkan secara langsung ke subjek dan dengan menggunakan bantuan google form agar dapat terdistribusi lebih cepat.

Subjek penelitian ini yaitu semua perawat di Rumah Sakit Charlie Hospital, Kendal yang berjumlah 35 orang yang tersebar dalam semua instalasi pelayanan. Teknik analisis data yang digunakan pada penelitian ini yaitu menggunakan analisis regresi, dan data tersebut diolah dengan menggunakan perangkat lunak SPSS versi 22 for windows. Analisis regresi ini digunakan untuk menghitung besarnya pengaruh antara variabel bebas, yaitu turnover intention dan variable terikat kepuasan kerja.

Model dari penelitian ini digambarkan pada gambar dibawah ini :

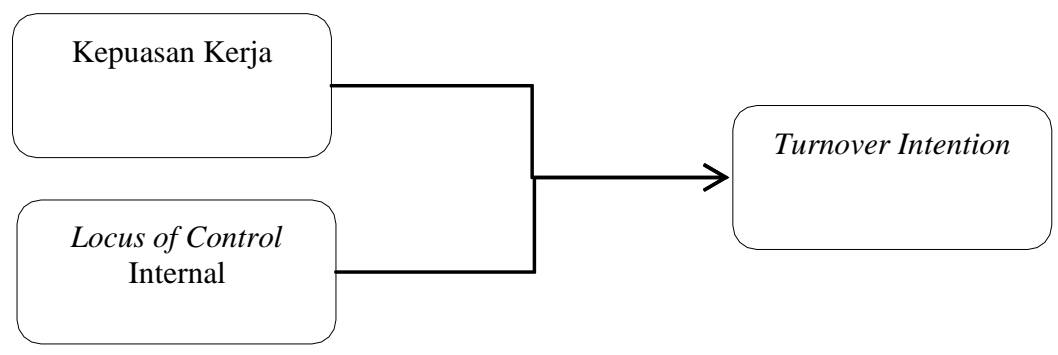

Gambar 1. Model Penelitian

Berdasarkan gambar 1. model penelitian maka didapatkan h1 dari penelitian ini adalah terdapat hubungan antara kepuasan kerja, locus of control internal dengan turnover intention pada perawat di Rumah Sakit Charlie Hospital, sedangkan h0 dari penelitian ini yaitu tidak terdapat hubungan antara kepuasan kerja, locus of control internal dengan turnover intention pada perawat di Rumah Sakit Charlie Hospital.

\section{HASIL DAN PEMBAHASAN}

Berdasarkan hasil yang didapatkan dari kuisioner yang disebarkan kepada 35 orang perawat di Rumah Sakit Charlie Hospital dan didapatkan hasil :

Tabel 1. Deskripsi Kuisioner

\begin{tabular}{|c|c|c|c|c|c|}
\hline Variabel & $\mathbf{N}$ & Minimum & Maximum & Mean & $\begin{array}{c}\text { Standard } \\
\text { Deviation }\end{array}$ \\
\hline Kepuasan Kerja & 35 & 2.00 & 3.92 & 2.59 & 0.39 \\
\hline Locus of Control Internal & 35 & 0.10 & 0.65 & 0.30 & 0.12 \\
\hline Turnover Intention & 35 & 1.93 & 3.14 & 2.49 & 0.31 \\
\hline
\end{tabular}

Gufa Bagus Pamungkas ${ }^{2}$, Heru Sulistyo ${ }^{2}$ - The Relationship Of Job Satisfaction And Internal Locus Of Control With Turnover... [Vol 11, No 1 (2020): April 2020] JBTI 
Berdasarkan hasil yang didapatkan pada kategori kepuasan kerja akan di golongkan dalam 4 kategori: 1.00-1.75 (sangat tidak puas), 1.76-2.50 (tidak puas), 2.51-3.25 (puas), 3.26-4.00 (sangat puas). Pada turnover intention juga digolongkan dalam 4 kategori 1.00-1.75 (sangat tinggi), 1.762.50 (tinggi), 2.51-3.25 (rendah), 3.26-4.00 (sangat rendah). Skor locus of control internal hanya memiliki 2 kategori 0.00-0.50 (Internal), sedangkan 0.51-1.00(Eksternal).

Sehingga berdasarkan tabel I. Pada nilai rerata dapat diketahui bahwa kepuasan kerja perawat di Rumah Sakit Charlie Hospital tergolong pada kategori puas, sedangkan turnover intention perawat di Rumah Sakit Charlie Hospital Kendal tergolong tinggi, dan perawat memiliki locus of control internal.

Detail kepuasan kerja perawat di Rumah Sakit Charlie Hospital, Kendal dideskripsikan dalam gambar dibawah ini:

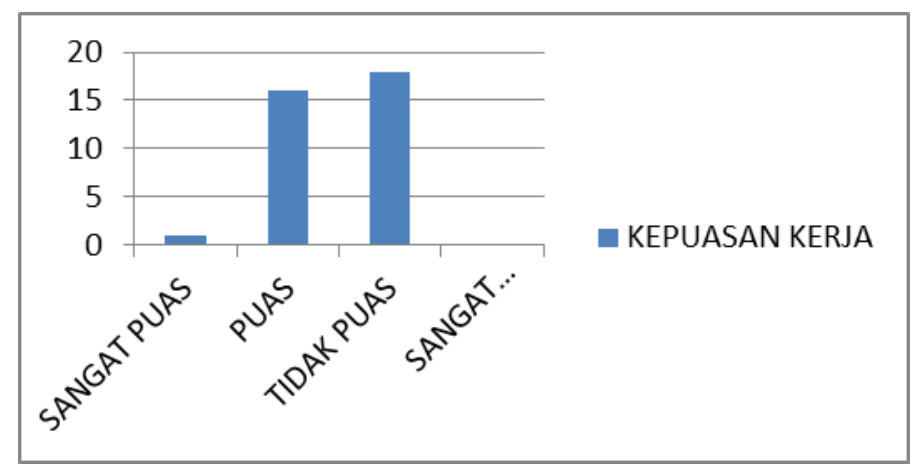

Gambar 2. Kepuasan kerja perawat di Rumah Sakit Charlie Hospital, Kendal

Berdasarkan gambar 2. Didapatkan bahwa sebanyak 1 orang/2.86\% perawat di Rumah Sakit Charlie Hospital Kendal merasa sangat puas, sebanyak 16 orang/45.71\% merasa puas, sebanyak 18 orang $/ 51.43 \%$ merasa tidak puas, dan tidak ada satupun perawat yang tergolong pada kategori sangat tidak puas.

Hasil dari kuisioner kepuasan kerja yang mendapatkan rerata skor paling rendah yaitu pada aspek gaji. Pada pernyataan yang berbunyi "kepuasan terhadap berbagai jenis tunjangan yang ada" memiliki rerata skor 2.11 yaitu pada kategori tidak puas, pernyataan lain yang berbunyi "kepuasan terhadap kenaikan gaji” juga memiliki rerata skor 2.17 yang tergolong dalam kategori tidak puas, serta pernyataan terkait "kepuasan dengan tingkat gaji" memiliki rerata skor 2.28 yang juga tergolong pada kategori tidak puas. berdasarkan keterangan salah satu perawat hal tersebut dikarenakan gaji pekerjaan sebelumnya lebih tinggi, karena sebagian besar perawat yang bekerja di Rumah Sakit Charlie Hospital Kendal sebelumnya bekerja di kota semarang mengingat lokasi Rumah Sakit Charlie Hospital ada di perbatasan kabupaten Kendal dan kota Semarang, sehingga salah seorang perawat menyatakan hal tersebut wajar karena upah minimum kota semarang dan kabupaten Kendal berbeda, dimana otomatis akan mempengaruhi gaji perawat, namun perawat tersebut berharap agar hal tersebut tetap menjadi perhatian pihak manajemen seiring dengan perkembangan Rumah Sakit Charlie Hospital.

Deskripsi locus of control perawat di Rumah Sakit Charlie Hospital, kendal tergambar pada gambar dibawah ini:

Gufa Bagus Pamungkas ${ }^{2}$, Heru Sulistyo ${ }^{2}-$ The Relationship Of Job Satisfaction And Internal Locus Of Control With Turnover... [Vol 11, No 1 (2020): April 2020] JBTI 


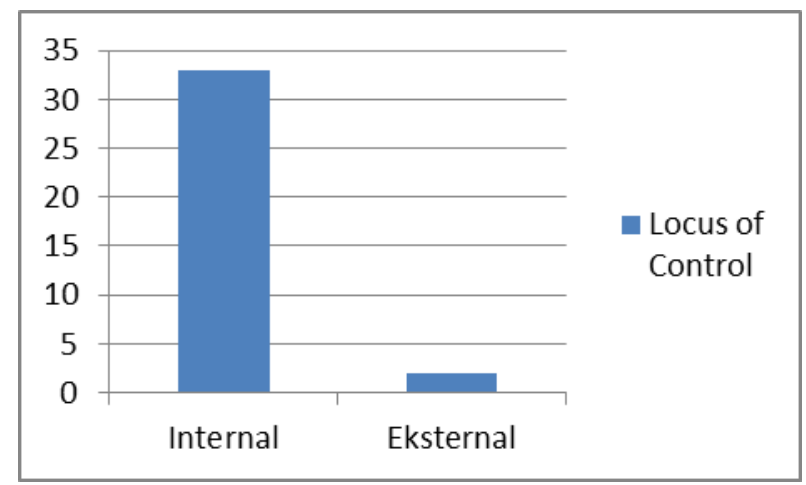

Gambar 3. Locus of Control perawat di Rumah Sakit Charlie Hospital, Kendal

Berdasarkan gambar 3. Didapatkan bahwa sebanyak 33 perawat/94.29\% memiliki locus of control internal, sedangkan sebanya 2 perawat/5.71\% perawat memiliki locus of control eksternal. Hal tersebut dikarenakan mereka sebagai tenaga professional serta berpendidikan tinggi merasa sudah mengetahui apa yang mereka lakukan baik terkait manfaat serta resikonya, sebagian besar dari perawat tidak suka mendapat intervensi dari siapapun. Untuk pernyataan yang paling menonjol terkait yaitu terkait "Kesuksesan yang saya peroleh sebagian besar merupakan Kebetulan" memilik rerata skor 0.02 , hasil wawancara dari perawat menyatakan bahwa dalam dunia ini tidak ada yang kebetulan, apa yang diusahakan pasti akan dituang hasilnya. Mereka menyadari ketika melakukan pekerjaan dengan sungguh-sungguh akan mempengaruhi karir mereka kedepanya.

Turnover intention perawat di Rumah Sakit Charlie Hospital, Kendal yang menjadi salah satu variabel penelitian ini dideskripsikan dalam gambar dibawah ini:

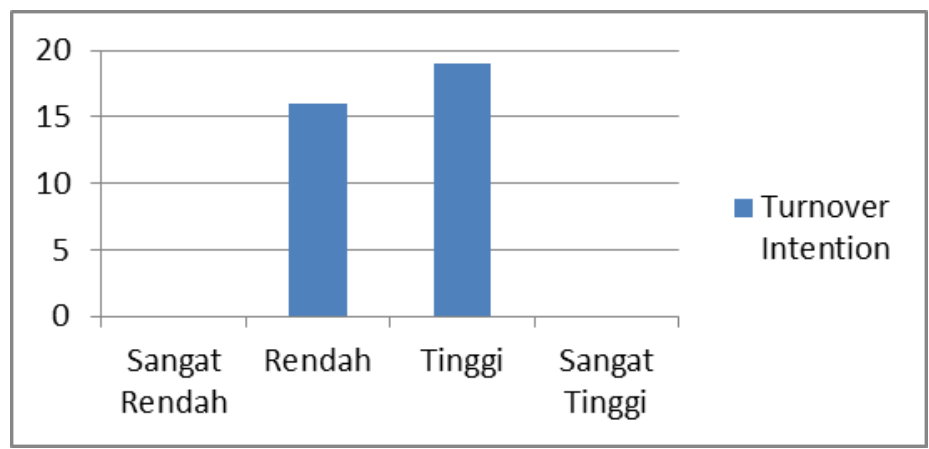

Gambar 4. Turnover Intention perawat di Rumah Sakit Charlie Hospital, Kendal

Berdasarkan gambar 4 didapatkan sebanyak 19 perawat/57.14\% di Rumah Sakit Charlie Hospital memiliki turnover intention pada kategori tinggi, dan sisanya sebanyak 16 perawat $/ 42.86 \%$ memilik turnover intention yang rendah, dan tidak satupun perawat yang masuk dalam kategori turnover intention sangat tinggi, begitu pula pada kategori turnover intention sangat rendah.

Hasil dari kuisioner turnover intention yang memiliki skor paling rendah yaitu pada pernyataan "Saya berpikir tentang membuka bisnis saya sendiri" mendapatkan rerata skor 2.14 yaitu termasuk dalam kategori turnover intention yang tinggi. Berdasarkan wawancara dengan beberapa perawat merka memimpikan memiliki usaha sendiri karena menjadi pengusaha tidak memiliki jam kerja dan tidak terikat dengan instansi manapun sehingga waktu bersama keluarga akan menjadi lebih fleksibel, apalagi ketika mereka sudah menginjak usia tidak produktif sebagai pekerja maka salah satu jalan agar menjadi tetap produktif adalah memiliki usaha sendiri.

Berdasarkan hasil data dari kuisioner, dilakukan analisis regresi dan didapatkan hasil berikut:

Gufa Bagus Pamungkas ${ }^{2}$, Heru Sulistyo ${ }^{2}$ - The Relationship Of Job Satisfaction And Internal Locus Of Control With Turnover... [Vol 11, No 1 (2020): April 2020] JBTI 
Tabel 2. Hasil Analisis Regresi Dengan Perangkat Lunak Spss Versi 22 For Windows

\begin{tabular}{|c|c|}
\hline Analisis Regresi & Signifikansi \\
\hline Kepuasan Kerja & 0.822 \\
\hline Locus of Control Internal & 0.765 \\
\hline
\end{tabular}

Dari hasi analisis regresi pada tabel II didapatkan angka signifikansi 0.822 pada variabel kepuasan kerja dan 0.765 pada variabel locus of control internal, dimana angka tersebut $>0.05$ yang berarti bahwa tidak terdapat hubungan antara kepuasan kerja, locus of control internal dengan turnover intention pada perawat di Rumah Sakit Charlie Hospital. Hal tersebut berseberangan dengan penelitian penelitian sebelumnya, yang mengatakan bahwa kepuasan kerja dan locus of control internal dapat menangani permasalahan turnover intention, hal tersebut juga bisa disebabkan karena sifat alamiah manusia yang sangat berubah-ubah atau tidak bisa ditebak. Sebagai sesuatu yang memiliki sifat kedinamisan, maka karakter kepribadian seseorang dapat berubah dan berkembang sejalan dengan perkembangan kemampuan cara berpikir seseorang dalam mempersepsikan sesuatu (Chairilsyah, 2012). Selain itu, bahwa manusia akan selalu berubah sesuai apa yang dipikirkanya, manusia bisa memiliki perubahan sikap hanya dalam hitungan detik, sehingga apa yang dipelajari pada studi sebelumnya belum tentu dapat sesuai dengan penelitian ini (Mustafa, 2011).

Tabel 3. Hasil Analisis Korelasi Pearson

\begin{tabular}{|c|c|}
\hline Jenis Tes & korelasi \\
\hline Kepuasan Kerja & 0.039 \\
\hline Locus of Control Internal & 0.052 \\
\hline
\end{tabular}

Pada penelitian ini juga dilakukan uji korelasi pearson dengan menghasilkan angka korelasi kepuasan kerja sebesar 0.039 dan korelasi locus of control internal sebesar 0.052 , dari angka korelasi tersebut berarti berdasarkan uji korelasi pearson juga dapat disimpulkan bahwa tidak terdapat hubungan antara kepuasan kerja dan locus of control internal dengan turnover intention, Selain itu cara untuk menginterpretasikan koefisien korelasi yaitu:

Tabel 4. Tabel Koefisien Korelasi (Sugiyono, 2012)

\begin{tabular}{|c|c|}
\hline Angka koefisien korelasi & Interpretasi \\
\hline $0.00-0.199$ & Sangat Rendah \\
\hline $0.20-0.399$ & Rendah \\
\hline $0.40-0.599$ & Sedang \\
\hline $0.60-0.799$ & Kuat \\
\hline $0.80-1.000$ & Sangat Kuat \\
\hline
\end{tabular}

Berdasarkan tabel 4. tersebut dapat diartikan hubungan antara variabel kepuasan kerja dan variabel turnover intention memiliki hubungan yang sangat rendah, dikarenakan angka $\mathrm{r}$ hitung pada analisis diatas sebesar 0.039 , maka penyebab tingginya angka turnover intention dipengaruhi oleh variabel lain dengan prosentase sebesar $96.1 \%$. hubungan antara variabel locus of control internal dan variabel turnover intention memiliki hubungan yang sangat rendah, dikarenakan angka $\mathrm{r}$ hitung pada analisis diatas sebesar 0.052, maka penyebab tingginya angka turnover intention dipengaruhi oleh variabel lain dengan prosentase sebesar $94.8 \%$.

Menurut Wahyuni dkk. (2014) faktor-faktor yang mempengaruhi analisis turnover intention dari segi faktor internal yaitu komitmen organisasi dan hubungan dengan atasan sedangkan faktor eksternalnya gaji dan insentif serta sikap atasan, sedangkan pada penelitian lain menjelaskan bahwa

Gufa Bagus Pamungkas ${ }^{2}$, Heru Sulistyo ${ }^{2}-$ The Relationship Of Job Satisfaction And Internal Locus Of Control With Turnover... [Vol 11, No 1 (2020): April 2020] JBTI 
faktor paling besar yang mempengaruhi keluarnya karyawan dari pekerjaan yaitu jika mendapatkan tawaran atau kesempatan menjadi aparatur sipil negara (ASN) karena menjadi ASN dianggap memiliki masa depan yang pasti, namun jika di perusahaan swasta masih memiliki kemungkinan terjadi gulung tikar (Manurung dan Ratnawati, 2012).

Berdasarkan hasil wawancara dengan beberapa perawat di Rumah Sakit Charlie Hospital mendapatkan hasil bahwa variabel lain yang membuat mereka ingin berhenti kerja yaitu terkait beban kerja yang begitu tinggi, menurut mereka jumlah perawat yang masih sedikit membuat beban kerja perawat menjadi sangat menumpuk, sehingga menimbulkan stres pada perawat. Pendapat lain berkata bahwa Rumah Sakit Charlie Hospital sebagai rumah sakit baru menimbulkan kekhawatiran terkait masa depan Rumah Sakit Charlie Hospital apakah dapat berkembang terus atau tidak, karena kemungkinan apapun bisa terjadi dalam suatu perusahaan swasta.

Hasil wawancara perawat lain juga berpendapat bahwa keinginan menjadi Aparatur Sipil Negara (ASN) juga menjadi salah satu hal yang membuat perawat Rumah Sakit Charlie Hospital, kendal ingin mengundurkan diri, menurut mereka apabila mereka diterima menjadi aparatur sipil Negara (ASN) maka mereka sangat mungkin sekali untuk mengundurkan diri dari pekerjaan, menjadi ASN menurut mereka dianggap lebih menjamin hidup mereka dalam segala aspek, serta selain itu juga karena tuntutan keluarga yang lebih merekomendasikan menjadi ASN daripada menjadi pegawai swasta.

\section{KESIMPULAN DAN SARAN}

Berdasarkan hasil penelitian tentang hubungan antara kepuasan kerja dan turnover intention pada perawat di Rumah Sakit Charlie Hospital yang telah dilakukan pada 35 orang perawat didapatkan bahwa rata-rata perawat di Rumah Sakit Charlie Hospital tergolong puas pada hal kepuasan kerja, namun pada aspek gaji memiliki rerata kepuasan yang paling rendah. Perawat di rumah sakit Charlie Hospital memiliki kecenderungan locus of control internal, hal tersebut dikarenakan hampir semua perawat meyakini apa yang dikerjakan sekarang merupakan apa yang akan didapatkan dimasa depat, tidak ada kesuksesan yang dating tiba-tiba sehinggan sangat diperlukan kesungguhan dalam menjalani pekerjaan mereka sebagai perawat. Turnover intention perawat di Rumah Sakit Charlie Hospital tergolong pada kategori tinggi, aspek yang paling mempengaruhi hal ini yaitu keinginan perawat untuk membuka usaha sendiri. Mereka menganggap memiliki usaha sendiri akan memberikan kebebasan waktu dan mengatur organisasinya sendiri sehingga waktu untuk bertemu dengan keluarga lebih fleksibel dan bisa diatur.

Kesimpulan utama dari penelitian ini yaitu tidak terdapat hubungan antara kepuasan kerja, locus of control intenal dengan turnover intention pada perawat, karena ternyata masih ada variabel lain yang juga mendorong perawat di Rumah Sakit Charlie Hospital untuk berhenti bekerja. Faktor lain yang didapatkan dari pernyataan perawat di Rumah Sakit Charlie Hospital yaitu beban kerja yang tinggi, stress kerja, kekhawatiran terkait perkembangan rumah sakit mengingat Rumah Sakit Charlie Hospital masih tergolong baru, serta tawaran untuk menjadi aparatur sipil Negara (ASN).

\section{DAFTAR PUSTAKA}

Allen, D. G., Bryant, P., \& Vardaman, J. (2010). Retaining Talent: Replacing Misconceptions With Evidence-Based Strategies. Academy of Management Perspectives, 48-64.

Blau, G. J. (1987). Locus of control as a potential moderator of turnover intention. Journal of Occupational Psychology, 21-29.

Chairilsyah, D. (2012). Pembentukan Kepribadian Positif Anak Sejak Usia Dini. Educhild, 1-7.

Daniels, C. S., Mackovjak, J., Audia, J., \& Richards, S. (2013). Stop the revolving door: Implement retention initiatives that work. Nursing Management, 40-47.

Firdaus, A. (2017). Faktor-faktor yang Mempengaruhi Turnover Intention. Jurnal of Economics and Business, 1-7.

Gufa Bagus Pamungkas ${ }^{2}$, Heru Sulistyo ${ }^{2}-$ The Relationship Of Job Satisfaction And Internal Locus Of Control With Turnover... [Vol 11, No 1 (2020): April 2020] JBTI 
Ikhwanto, J. (2015). Hubungan Antara Kepuasan Kerja Dengan Intensi Turnover Pada Karyawan. $U M S$.

Jeon, J. H., \& Yom, Y.-H. (2014). Roles of empowerment and emotional intelligence in the relationship between job embeddedness and turnover intension among general hospital nurses. Journal of Korean Academy of Nursing Administration, 302-312.

Lin, C.-P., \& Ding, C. (2005). Moderating Effect of the Locus of Control on the Process of Turnover Intentions for High-Tech Personnel. Asia Pacific Management Review, 303-313.

Manurung, M. T., \& Ratnawati, I. (2012). Analisis Pengaruh Stres Kerja Dan Kepuasan Kerja Terhadap Turnover Intention Karyawan (Studi Pada STIKES Widya Husada Semarang). Jurnal Administrasi Bisnis, 145-157.

Mattox, J., \& Darryl L., J. (2005). Using survival analysis to demonstrate the effects of training on employee retention. ELSEVIER, 423-430.

Mazurenko, O., Gupte, G., \& Shan, G. (2015). Analyzing U.S. nurse turnover: Are nurses leaving their jobs or the profession itself? Journal of Hospital Administration, 48-56.

Mustafa, H. (2011). Perilaku Manusia dalam Perspektif Psikologi Sosial. Jurnal Ilmu Administrasi Bisnis, 143-156.

Pawesti, R., \& Wikansari, R. (2016). Pengaruh Kepuasan Kerja terhadap Intensi Turnover Karyawan di Indonesia. Jurnal Ecopsy, 50-67.

Prabowo, A., \& Heriyanto. (2013). Analisis Pemanfaatan Buku Elektronik ( E-Book ) oleh Pemustaka di Perpustakaan Sma Negeri 1 Semarang. UNDIP e-journal, 1-9.

Purnamasari, I., \& Kapalawi, I. (2013). Analysis of Human Resource Management Process in Stella Maris Hospital Makassar. JURNAL MKMI, 120-124.

Ramadhani, S. A. (2019). Pengaruh Kepuasan Kerja terhadap Turnover Intention Dimoderasi Locus Of Control Internal. UMM.

Ripiinen, M. (2010). Extrinsic Occupational Needs and the Relationship Between Need for Achievement and Locus of Control. The Journal of Psychology, 577-587.

Sarah, S., Pelealu, F., \& Maramis, F. (2015). Hubungan Antara Promosi dan Kompensasi Dengan Kepuasan Kerja Perawat di Rumah Sakit Umum Pancaran Kasih Gmim Manado. FKM Unsrat.

Sari, N. R., Hakam, M., \& Susilo, H. (2015). Pengaruh Kepuasan Kerja terhadap Turnover Intention (Studi pada AJB Bumiputera 1912 Kantor Wilayah Jatim II/Malang). Jurnal Administrasi Bisnis, 1-8.

Soeroso, S. (2003). Manajemen Sumber Daya Manusia di Rumah Sakit: Suatu Pendekatan Sistem. Jakarta: EGC.

Sugiyono. (2012). Metode Penelitian Pendidikan, Pendekatan Kuantitatif, Kualitatif, dan R\&D. Bandung: Alfabeta.

Wahidmurni. (2017). Pemaparan Metode Penelitian Kuantitatif. UIN Malang.

Wahyuni, A. S., Zaika, Y., \& Anwar, R. (2014). Analisis Faktor-faktor yang Mempengaruhi Turnover Intention (Keinginan Berpindah) Karyawan pada Perusahan Jasa Konstruksi. Jurnal Rekayasa Sipil, 89-95.

Gufa Bagus Pamungkas ${ }^{\text {}}$, Heru Sulistyo ${ }^{2}$ - The Relationship Of Job Satisfaction And Internal Locus Of Control With Turnover.. [Vol 11, No 1 (2020): April 2020] JBTI 